\title{
Indledning
}

\section{Liv og død}

\author{
Af Charlotte Kroløkie, \\ Tine TJøRnhøJ-Thomsen OG \\ Marianne KongersLeV
}

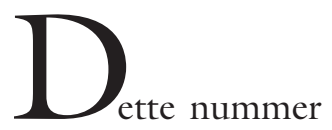

handler om liv og død. Vi stiller skarpt på livet, men inddrager også døden som en uomgxngelig dimension af livet og som en, der er underteoretiseret i kønsforskningen. Vi diskuterer derfor ikke blot livets politik (Rose 2006) men også nekropolitik (Mbembe 2003). Danske kønsforskere har allerede analyseret livets begyndelse, herunder hvordan celler bliver til liv på fertilitetsklinikken (Tjørnhøj-Thomsen 2002, Adrian 2006) samt hvordan fosterlivet og det kommende liv som forældre iscenesættes i tredimensionelle ultralydsscanninger (Kroløkke 2011). Reproduktionsteknologierne bliver aktører i skabelsen af nyt liv og redefinerer derved vores forståelser af slægtskab. Vi mener, at dødsteknologierne tilsvarende rejser en kxde af relevante spørgsmål, herunder hvilke liv og hvilken død er (u)værdig(e)?

Skæringen mellem liv og død er ikke altid ligetil. Nedfrysningsteknologier skaber eksempelvis nye forståelsesrammer for græn- 
sesætningerne mellem liv og død. Når børn får konstateret en livstruende sygdom, hvor behandlingen kan forårsage sterilitet, får de i Danmark tilbud om fertilitetsbevarende behandling. I pigernes tilfælde kan xggestokkevæv blive udtaget og kryopræserveret for senere, når sygdommen er bekæmpet, at blive optøet og transplanteret. Ovarievævet transplanteres tilbage til pigens krop, men ikke nødvendigvis til underlivet, men til underarmen, hvor det er nemmere at fjerne modne xg til befrugtning. Tilsvarende får drenge, der endnu ikke er gået i puberteten og derfor ikke kan producere sæd, snart et tilsvarende tilbud om kryopræservering af testikelvæv. Livet og døden skal ikke forstås som naturlige modsætninger, men snarere, som Michael Hviid Jacobsen (2014) argumenterer, som naturlige sameksistenser.

Liv såvel som død kan anskues som vedvarende betydningsskabende processer, hvilket fx tydeliggøres i bioetiske diskussioner. Er det eksempelvis en menneskeret at kunne bestemme over, hvilket liv det er værd at leve? Når for eksempel en gravid kvinde på ultralydsskanningen får at vide og kan se, at fostret mangler en kropsdel, skal hun da selv kunne bestemme, hvad der for hende er en svær misdannelse, og som derved kan berettige en abort efter 12. uge? Skal en kronisk lidende person kunne træffe et valg om at afslutte sit liv, når livet ikke længere synes værd at leve? I dette nummer interesserer vi os for, hvordan feministiske teorier og metoder kan anvendes for at få en nuanceret adgang til så komplekse emner.

Tabubelagte emner som aktiv dødshjælp, abortturisme, organdonation, værdige og uværdige liv er i spil samtidig med, at vi gerne vil dø naturligt og smukt. Michael Hviid Jacobsen (2014) taler om en romantisering af døden, hvor hverken slanger eller maskiner står centralt; en død, hvor den døende til det sidste er omgivet af nære og kære. Men grænsesætningen mellem liv og død er hverken entydig eller stabil. Det ser vi også i anvendelsen af døde mænds sæd til fertilitetsbehandlinger. Israelske soldater kan nedfryse deres sæd og dermed give deres forældre muligheden for at videreføre slægten og blive bedsteforældre i fald de skulle dø. Her bliver liv og død sammenkoblet med udødelighed eller rettere videreførelsen af den jødiske familie.

Dødsritualer er også fortællinger om livet. Landsforeningen for Liv \& Død arbejder for en værdig afsked med livet og minder os om vigtigheden af at planlægge døden længe før, den indtræffer. Det kommer til udtryk på en særlig måde i Japan. Her er det blevet mere almindeligt, at japanere planlægger deres død gennem deltagelse i såkaldte "End of Life" seminarer i Tokyos største varehus Aeon, hvor den aldrende japanske befolkning kan afprøve kister og få taget billeder. Liv såvel som død bliver sat $\mathrm{i}$ scene, disciplineret og reguleret gennem på forhånd fastlagte normer og forventninger.

I dette temanummer spørger vi, hvad de feministiske perspektiver kan bibringe forståelserne af liv og død. Feministiske perspektiver sætter ikke alene fokus på køn. De stiller sig grundlæggende kritisk og spørgende til "naturligheder", herunder gængse forståelser af liv og død. Kan vi tænke døden i samme forståelsesramme som livet? Kan vi tale om tilblivelses- og afviklingsprocesser? Er fortællinger og forhandlinger omkring død og sorg en central del af konstitueringerne af liv og de materialiseringsprocesser, der gør livet forståeligt? Hvilken rolle spiller sorg og død i livet? Hvordan kan feministiske perspektiver indramme, hvordan vi forstår det at miste? Og ikke mindst hvad (eller hvem), der kan eller bør sørges?

Artiklerne i dette nummer af Kvinder, Køn og Forskning angriber emnet fra en række forskellige vinkler og videnskabelige traditioner. Således handler artiklerne både om døde homoseksuelle, kroppe, homoseksuel- 
le mænd, der gennem surrogatmoderskab får (nyt) reproduktivt liv som forældre samt forhandlinger af såvel liv og død.

I artiklen "Når enden er god. Heteronarrativitet og døde homoer" anlægger Dag Heede et queerteoretisk perspektiv på udvalgte litterære værker og illustrerer, hvordan køn, seksualitet og død hænger uløseligt sammen. Den homoseksuelle kæmper for sin eksistensberettigelse i de litterære værker. Således er "den gode homo" ofte "en død homo". Heede peger på et stort ufortalt forskningspotentiale i nordisk litteratur, der blandt andet også skal rammesættes $\mathrm{i}$ lyset af nationale projekter som velfærdsstaten.

Asta Smedegaard kobler køn, hvidhed og nationalitet sammen i artiklen "Utøya rører dig i hjertet' - Om hvidhed, nationalisme og nordiskhed i dansk tv-nyhedsformidling om 22. juli-terroren". Smedegaard viser i sin affektteoretiske analyse, hvordan den nyhedsjournalistiske formidling giver seerne mulighed for at identificere sig med ofrene samtidig med, at nyhedsformidlingen genetablerer det nordiske som først og fremmest hvid og "farveblind" i sorgarbejdet.

I artiklen "Moren er Død, Moren Leve" viser Michael Nebeling, hvordan homoseksuelle mænd søger at erobre et levedygtigt moderskab gennem surrogatmoderskab. Analysen bygger på interview med danske homoseksuelle par, der har benyttet sig af surrogatmoderskab i USA og i Indien. Den homoseksuelle figur som ufrugtbar (og derfor 'død') bliver i interviewene genforhandlet gennem nationale og heteronormative logikker således, at den homoseksuelle får adgang til det reproduktive liv.

Nico Miskow Friborg undersøger i artiklen “'Fjern dig så og dø’ - Det mexicanske tredjekøn muxes' involveringer og forhandlinger af heteronormativitet, familie og død" de tilblivelses- og afviklingsprocesser muxes indgår i. Gennem en analyse af queer slægtskaber belyser Friborg, hvordan muxes forhandler en plads i familien ved at rekonfigurere (hetero)normer for slægtskaber og ikke mindst døden.

Mathias Ericson interesserer sig i sin artikel "Vem dör? Genus, sårbarhet och beskydd i olycksförebyggande arbete" for, hvordan tolkning af dødsfaldsstatistik inden for ulykkesforebyggende arbejde kan sxttes i relation til spørgsmål om maskulin beskyttelse og de seneres års øgede fokus på risici og trusler. Ericson fokuserer på, hvad der sker, når idealet om maskulin beskyttelse sættes overfor statistik, som viser, at mænd er særligt risikoudsatte og har behov for beskyttelse. Men at beskrive mænd som en sårbar gruppe kommer, viser Ericson, samtidig på kollisionskurs med dominerede forventninger til at mænd distancerer sig fra sårbarhed og udsathed. Det er disse modstridende overlapninger mellem maskulinitet, sårbarhed og beskyttelse, som denne artikel behandler.

Om kunst, køn og nekropolitik hos den mexicanske samtidskunstner Teresa Margolles" tager ph.d. Mikkel Krause Frantzen udgangspunkt i Mbembes begreb nekropolitik og analyserer, hvordan Margolles gentænker æstetiske repræsentationer af de grusomme kvindemord ('femicides'), der siden 1993 har hjemsøgt Ciudad Juárez og resten af Mexico. Margolles tæller bogstaveligt de døde kvinder, og med Butlers begreb om "ungrievable life" diskuterer Frantzen den måde hun italesætter denne usørgbarhed i sin kunstneriske praksis, som er stærkt inspireret af hendes baggrund indenfor retsmedicin.

I "Den homosociale voldtægtskultur", som er dette nummers eneste artikel udenfor tema, undersøger Sara Gjermandsen, hvordan hun med etableringen af en ny strukturel model kan bidrage til en ny læsning af 
utopisk og dystopisk feministisk fiktions repræsentation- og forhandling af begrebet voldtægtskultur.

God læselyst!

Temaredaktører

Charlotte Kroløkke, Tine Tjørnhøj-Thomsen og Marianne Kongerslev

\section{LITERATURE}

- Adrian, Stine (2006): Nye skabelsesberetninger om ag, sed og embryoner : et etnografisk studie af anvendelsen af assisteret befrugtning på sadbanker og fertilitetsklinikker. Linköping Studies in Arts and Science, Nr. 370.

- Jacobsen, Michael Hviid (2014): 'Mit liv', 'Min vilje' og 'Min død' - medbestemmelse som selvbestemmelse i den senmoderne skabelse af 'den gode død'. Omsorg: Nordisk tidsskrift for Palliativ Medisin. Vol. 31 (2), 31-37.

- Kroløkke, Charlotte H. (2011): Biotourist Performances: Doing Parenting during the Ultrasound. Text and Performance Quarterly.Vol. 31 (1), 15-36.

- Mbembe, Achille (2003): Necropolitics, Public Culture, Vol. 15(1), 1-40.

- Rose, Nicholas (2006); The Politics of Life Itself: Biomedicine, Power, and Subjectivity in the TwentyFirst Century. Princeton: Princeton University Press.

. Tjørnhøj-Thomsen, Tine (2002): Fra barnløshed to forældreskab. Kvinder, Køn og Forskning, Vol. 11 (1) 5-18. 